\title{
Dilemma and Breakthrough of Regional Sharing of Higher Music Education Resources
}

\author{
Yu Heyong \\ Dalian Art College
}

Keywords: Higher education; Music; Resource; Sharing

\begin{abstract}
In the current information era, science and knowledge are developing rapidly. Higher music education undertakes the development and inheritance of music art. Therefore, it should adapt to characteristics of the era, break through "sectarianism", integrate and share advantaged resources and build the prosperity of one or multiple music art categories. Regional sharing of higher music education resources is an important aspect that needs exploration in the development of Chinese higher education, while the dilemma of regional sharing of higher music education resources reflects problems that the development of higher education is confronted with indirectly. Therefore, the analysis of the problems in regional sharing of higher music education resources and the proposal of strategies to the dilemma can promote the success of regional sharing of higher music education resources; meanwhile, it can promote the long-term development of Chinese higher music education.
\end{abstract}

\section{Function of regional sharing of higher music education resources}

Regional sharing of higher music education resources has important practical significance and necessity.

Firstly, regional sharing of higher music education resources can enhance competition advantages of colleges. Competition advantages of colleges are mainly represented in teaching quality and teaching environment, and general approaches of competition advantages are cost leadership and differentiation. On the one hand, regional sharing of resources can extend the usage of educational resources of colleges from inside campus to the outside, which can both save the cost and endow prerequisites to major advantages, school-running forms, admission ranges and expansion of scale of single colleges. On the other hand, regional sharing of resources can combine teaching equipment, book information and materials and faculty resources better, which can not only enhance resource utilization, but also play an important role to the development of teaching and scientific research functions of colleges and the improvement of education levels, the improvement of subject categories, the enriching of teaching forms and the enhancement of disciplinary majors.

Secondly, resource sharing can enhance advantages of colleges and improve industry property and professional property, thereby highlighting difference. Generally speaking, the boarder and wider the scope of college resource sharing, the stronger colleges' advantages, and the more prominent differentiation. Regional sharing of higher music education resources can create resource complementarity. Resource sharing can conquer weak links by relying on the external resources of single colleges so that their own advantaged resources can be strengthened by interschool approaches. On the one hand, resource sharing can improve the total quantity and category of resources that colleges can use; on the other hand, resource sharing can optimize resource allocation of different colleges. Therefore, the utilization range and efficiency of resources can be improved, and the quality of available resources can be improved.

Thirdly, regional sharing of higher music education resources has the advantage of broadening new resources. Economic globalization and the rapid development of science and technology have increased the uncertainty and opportunities of the external environment of colleges and future development. 


\section{Difficulties confronted by regional sharing of higher music education resources}

Sharing of educational resources have been advocated by the country, but from the perspective of the practical conditions of regional sharing of higher music education resources, it cannot achieve good sharing effects. From the inside of colleges, regional sharing of education resources is difficult to be realized, since it needs certain material basis or experiences that can be replicated. However, it will be different in school positioning and major positioning of different colleges. Meanwhile, it might be hugely different because of degrees of colleges and teaching quality in different colleges. Also, it might be influenced by teaching experiences. Teaching under different conditions might receive different results in different environment.

Based on the unduplicatedness of materials and teaching experiences, philosophies of regional sharing of higher music education resources are not profound enough; meanwhile, it also leads to the unduplicatedness of materials and teaching experiences. Firstly, the shallow philosophies of regional sharing of higher music education resources leads to the fact that regional sharing of higher music education resources stays at the level of material sharing and experience sharing, i.e., superficial sharing. For example, brotherly colleges often exchange needed products or send teachers to study and discuss educational problems. However, this kind of study is not sharing. It is merely pure academic discussion, and regional sharing of higher music education resources only explores very few things and the level is very shallow.

Secondly, from the perspective of materials, material resources and natural resources in regional sharing of higher music education resources are difficult to be replicated. For example, advantages of natural resources are quite distinct in higher education colleges in the southwest. Firstly, the open geographical environment can endow more open hearts to students so that students can have more imagination space and activity places; also, students can release their instincts sufficiently instead of being restricted in concrete teaching buildings. The second advantage is the closeness of natural environment. Nature is an important existence that cannot be ignored for human survival and development. Also, in natural environment, when people are experiencing and feeling nature by themselves, they can also learn much knowledge which do not exist in books. Music education is to cultivate students' ability of appreciating and creating beauty, and it is also the education to cultivate students' noble qualities and music qualities. However, such natural resources cannot be replicated comprehensively. Therefore, it is difficult to form good regional sharing of higher music education resources.

The shallow philosophies of regional sharing of higher music education resources leads to superficial methods and means of regional sharing of higher music education resources. After a long time of such sharing, it will also lead to superficial philosophies of regional sharing of higher music education resources. They will influence each other and eventually leads to problems in regional sharing of higher music education resources.

In Chinese regional sharing of higher music education resources, resource allocation is usually conducted by government and the country. Based on the importance of education, educational resource is monopolistic resource in Chinese education. Therefore, it is planning to some extent.

In Chinese education industry, the government has paid much attention to the stage of compulsory education, which is determined by the national condition of Chinese population. However, with definite government resource, if investment in compulsory education is strengthened, attention to higher education is bound to be less. In the end, higher education has to be self-reliant. However, such kind of self-reliance is restricted by the government. Therefore, resource base in higher education is weak. In the meantime, the country has different resource allocation policies for different colleges, and different resource allocation is confirmed according to different levels, which results to the closeness and opposition in college resource allocation. Every school is influenced by development history, development ways, teaching resource, disciplinary difference and so on, and they have many differences in resources. Though every college is exploring its own resource actively, many colleges have not made much progress in resource sharing.

The continuous improvement of Chinese overall national strength and economic and material basis is a comprehensive process. However, the allocation ways of college music educational 
resource are far behind the development of modernization and marketization.

In educational system of higher education, colleges have very few initiatives of school-running, which results to huge difference between college talent-cultivation system and social talent demand system. Under the influence of modernization and marketization, it is difficult to implement higher education reforms since they are restricted by multiple element. Therefore, various aspects of higher education are insufficient. Though various colleges are promoting educational reforms in various ways, the effects are not optimistic. From the perspective of regional sharing of higher music education resources, regional sharing of higher music education resources stays more at the level of schools, and there are many disadvantages in deep-level resource sharing and resource sharing that students can enjoy. From the perspective of schools, resource allocation is more applied in the construction, the investment of infrastructure and development fairness of key universities. Though it can relieve problems in regional sharing of higher music education resources to some extent, it is still difficult to adjust the future development trend and demands of marketization and modernization of regional sharing of higher music education resources.

\section{Breakthrough ways of regional sharing of higher music education resources}

To promote the further realization of regional sharing of higher music education resources, firstly, it should start from the formation of sharing from concept. To realize this purpose, the following aspects can be referred to.

Firstly, concerning the sharing of previous materials and teaching experiences, colleges should make their own choice according to their characteristics. The successful experiences of any school can be referred to, but cannot be used directly. This is determined by the characteristics of different colleges. The successful experiences of a college might be useful to itself. However, it might not be useful to other schools. Therefore, before resource sharing, schools should make sure of their own characteristics, successful resources and characteristics of experiences, thereby summarizing sharing resources and experiences that can be applied on themselves.

Secondly, further formation of sharing should be promoted actively. In many universities, regional sharing of higher music education resources is not an integrate concept. Normally, various discussions, seminars and conferences are used as sharing channels and realization ways. However, this is not resource sharing of modern significance. College staff's enthusiasm and initiative at sharing should be given full play, so they should have a fresh understanding of the significance and roles of sharing resources.

The distribution of higher music education resources is distinctly regional, which is mainly under the influence of management system in colleges. Regional sharing and integration of higher music education resources should start from two perspectives. Firstly, from the perspective of government, the government should pay more attention to regional sharing of higher music education resources and have more institutionalized construction and macroscopic coordination in regional sharing of higher music education resources. In addition, provincial and municipal governments of every region should abide by directions for regional sharing and allocation of higher music education resources. Also, they should promote the sharing of college resources according to the realistic conditions in the development of local colleges and resources in various colleges, thereby providing more policy guidance and capital support for the update of resources and better sharing of schools, promoting the enthusiasm and initiative of colleges in regional sharing of higher music education resources. In this way, regional sharing of higher music education resources can rise from the superficial level to the profound level and effective integration of regional sharing of higher music education resources can be promoted.

The country should promote regional sharing of higher music education resources to realize modernization and marketization. The update of educational resource of modernization and marketization is beneficial to stimulate the vitality of educational resources. Under the long-term influence of monopolized allocation, the circulation of educational resources is unsmooth, which results to the loss of vitality of regional sharing of higher music education resources. In order to promote the modernization and marketization of regional sharing of higher music education 
resources, the nation should start from the following aspects. Firstly, reduce the government's intervention in regional sharing of higher music education resources so that regional sharing of higher music education resources can circulate in a more open environment and the circulation of regional sharing of higher music education resources can be more efficient. Secondly, during the process of regional sharing of higher music education resources, the nation should strengthen the interaction between colleges and social resources. As the product of market economy, social resources have adapted to the development of marketization; meanwhile, they can also lead the development of market. Therefore, they are highly flexible, and they belong to marketization of practical level. Higher music educational resources have response and feedback to the market from theoretical perspective, and it is conclusive, practical and theoretical response to the market. The combination of social resources and higher education resources can promote the perceptiveness and theories of social resources so that higher music educational resources can have stronger reality and practicability. Therefore, the modernization and marketization of regional sharing of higher music education resources can be realized more effectively.

The development and reform of anything is not accomplished in an action, and it needs the accumulation of experiences and completion of practice. Higher music education is even more important and can never be neglected. Therefore, the nation should seek one or several music majors in colleges as pilots, explore and develop according to requirements of regional sharing of higher music education resources, complete gradually and form advantageous projects. On this basis, the sharing of major can be extended, thereby reaching bigger breakthrough of regional sharing of higher music education resources.

\section{Conclusion}

The dilemma confronted by regional sharing of higher music education resources is also the difficulty confronted by Chinese higher education. Therefore, the solution of these problems can also promote the development of Chinese higher education and realize students' effective, comprehensive and free development. "Sharing" is a hot word recently, and behind this word, it is the development trend of the whole marketization economy as well as the unavoidable trend of the future work of higher music education resources. Problems confronted by regional sharing of higher music education resources in this paper needs to be innovated from philosophy, methods and mechanism, thereby promoting the realization of the sharing objective of regional sharing of higher music education resources and promote the strengthening of Chinese education and the extension of comprehensive ability.

\section{References}

[1] Zheng Chunlong \& Shao Hongyan. Investigation and Reflection of Regional Sharing of Education Resources in Universities [J]. Higher Engineering Education Research. 2010(03)

[2] Ren Ke. On Sharing Approaches of College Seminar Resources [J]. Education Criticism. 2014(03)

[3] Zuo Chongliang \& Jiang Chungu. Research on Regional Sharing of University Scientific and Research Equipment [J]. Chinese University Science. 2011(06) 